\title{
Três lugares para a crise de legitimidade da ciência
}

\author{
Renan Springer de Freitas* \\ https://orcid.org/0000-0001-6109-6841
}

\begin{abstract}
Todos sabem que Einstein fez algo surpreendente, mas são poucos os que conhecem o que ele realmente fez.É geralmente reconhecido que ele revolucionou a nossa concepção do mundo físico, mas os novos conceitos estão envoltos no tecnicismo da matemática. Sem dúvida, há incontáveis explicações populares da teoria da relatividade, mas essas geralmente deixam de ser inteligíveis justamente quando começam a revelar o que é importante. Dificilmente se poderiam culpar os seus autores. Muitas das novas ideias podem ser expressas em linguagem não matemática, mas nem assim deixam de ser difíceis (Russell, 1974, p. 3).
\end{abstract}

Ao escrever essas linhas, em 1925, Bertrand Russell imaginou estar se referindo a uma dificuldade que deixaria de existir com o passar dos anos. Por essa razão, procurou atenuar o pessimismo que deixou transparecer em seu relato acrescentando o seguinte comentário: "As ideias de Einstein parecerão mais fáceis para as gerações que crescerem com elas" (Russell, 1974, p. 4). Os anos se passaram e isso não aconteceu. O futuro não repetiu o passado. As ideias de Copérnico, Galileu e Newton puderam parecer mais fáceis para as gerações que cresceram com elas, mas não as de Einstein, Max Planck, Erwin Schrödinger e dezenas de outros. Estas pareceram difíceis para as gerações que as viram surgir, para as que cresceram com elas e para as subsequentes; permanecem difíceis aos olhos das gerações do nosso próprio tempo e, ao que tudo indica, assim permanecerão por tempo indeterminado. Se no passado a ciência

* Universidade Federal de Minas Gerais, Belo Horizonte, Brasil. 
pareceu difícil, agora ela é difícil, difícil em si, como o asseverou Gaston Bachelard em sua obra Le matérialisme rationnel, de 1953. Consideremos, por exemplo, esses dois enunciados que coloco entre parênteses para facilitar a visualização: $\left(_{13} 27 \mathrm{Al}\right.$ $\left.+{ }_{2} 4 \alpha \rightarrow{ }_{15} 30 \mathrm{P}+{ }_{0} 1 \mathrm{n}\right)$ e $\left({ }_{15} 30 \mathrm{P} \rightarrow{ }_{14} 30 \mathrm{Si}+{ }_{+1} 0 \beta\right)$. Trata-se de duas equações de reação nuclear que, combinadas, enunciam a radioatividade induzida artificialmente, uma descoberta que, em 1934, convulsionou parte do conhecimento até então produzido pela chamada "ciência da matéria" (Bachelard, 1990, p. 245). Um feito de tal natureza ilustra particularmente bem o que eu ousaria chamar de "a sina da ciência contemporânea": ver-se frequentemente convulsionada por enunciados que contrariam o bom senso. Como pode um conhecimento marcado por essa "sina" ser assimilado pelo conhecimento comum? Muito fácil responder: não pode. Conclusão: se outrora havia como aproximar o conhecimento científico do conhecimento comum, agora já não há mais como fazê-lo.

No início da década de 1960, o historiador da ciência Thomas Kuhn (Kuhn, 1962) chegou a esta mesma conclusão por um caminho diferente: não o das descobertas contraintuitivas que subitamente revolvem todo um conhecimento já sedimentado, mas o do próprio processo por meio do qual um novo conhecimento vem a se sedimentar após o anterior ter sido revolvido. Em linhas gerais, esse processo pode ser descrito da seguinte maneira: para que exista ciência é necessário que alguma área de estudos seja capaz de produzir uma obra paradigmática que abra, de forma exemplar, todo um campo para a investigação empírica. Uma vez aberto esse campo, o próprio ato de explorá-lo gera "quebra-cabeças" que sempre se renovam. A atividade rotineira de buscar soluções para esses quebra-cabeças requer o domínio de um vocabulário próprio, hermético, esotérico, crescentemente especializado, concebido no rastro do vocabulário peculiar à obra paradigmática que abriu o campo de investigação a ser explorado. Visto que o conhecimento que resulta dessa atividade não é outro senão o conhecimento científico, segue-se, por um lado, que este tende a tornar-se cada vez mais impermeável ao conhecimento comum e, por outro, que seu desenvolvimento depende muito mais do treinamento especializado requerido para a solução dos referidos "quebra-cabeças" do que de uma supostamente desejável “abertura” para o acolhimento de novas ideias. Lamentável? Não, responderia Kuhn. Apenas um sinal de que a ciência está evoluindo. Somente em "protociências" nada disso acontece.

Entretanto, em um passado nem tão distante houve quem visse nesse quadro que acabo de descrever um motivo para desolação. Refiro-me, especialmente, a José Ortega y Gasset. Em seu célebre La rebelión de las masas, obra publicada em 1929 reunindo artigos escritos desde 1926, ele afirmou: "convém repisar a extravagância deste fato inegável: a ciência experimental progrediu em boa parte mercê do tra- 
balho de homens fabulosamente medíocres e menos que medíocres. Isto significa que a ciência moderna, raiz e símbolo da civilização atual, deu guarida dentro de si ao homem intelectualmente médio e lhe permite operar com bom êxito" (Ortega y Gasset, 2001, p. 61). O "homem intelectualmente médio" ao qual é permitido "operar com bom êxito" a que Ortega y Gasset se refere com nítido desdém por volta de 1930 não é outro senão esse homem especialmente bem treinado para solucionar "quebra-cabeças" que posteriormente Kuhn viria a chamar de "cientista normal". Mas Ortega y Gasset não estava sozinho em seu desalento. Em 1931, foi a vez de Karl Jaspers exprimir sua desilusão com a ciência do seu tempo ao publicar Die geistige Situation der Zeit, traduzido para o inglês, em 1935, sob o título Man in the Modern Age. Nessa mesma época, Johan Huizinga e Edmund Husserl fizeram o mesmo ao publicarem, respectivamente, em 1935 e em 1936, as obras hoje disponíveis em português sob os títulos Nas sombras do amanhã: diagnóstico da enfermidade espiritual do nosso tempo e A crise das ciências europeias e a filosofia transcendental.

Essas breves consideraçôes remetem diretamente ao tema que me foi proposto abordar no presente dossiê: a "crise de legitimidade da ciência". Na presente contribuição defendo a tese de que "crise de legitimidade da ciência" é um fenômeno para o qual há três "lugares", dois dos quais imaginários: o mundo celestial a que somos conduzidos pelas páginas de livros tais como os quatro que acabo de citar, e, em diametral oposição, o mundo dantesco a que somos levados por escritos libertários bem-intencionados tais como, por exemplo, os do filósofo da ciência Paul Feyerabend, a quem oportunamente retorno. O terceiro lugar é aquele a que somos conduzidos pelos escritos dos grandes intelectuais e cientistas da Alemanha da República de Weimar. Conforme pretendo mostrar, este é o único lugar que existe de fato, e não apenas na imaginação de determinados pensadores e nas páginas dos livros por eles escritos.

No mundo a que me referi como "celestial", a ciência não teria os atributos que tem e, exatamente por tê-los, sua legitimidade estaria permanentemente em questão. Já vimos o caso de Ortega y Gasset. Vejamos rapidamente os outros. Karl Jaspers lamentava o fato de viver em um mundo no qual a objetividade do conhecimento científico era incompatível com as verdades profundas e duradouras contidas nos mitos e nas reflexões mais bem sedimentadas do conhecimento comum (Jaspers, 1951; Everett, 1937, p. 360). Johan Huizinga, da mesma forma, lamentava o fato de as teorias científicas, principalmente no campo das ciências exatas, terem se afastado de tudo o que pode ser representado e compreendido de modo intuitivo nos termos 
do pensamento cotidiano (Huizinga, 2017; Trizio, 2016, p. 193). Husserl é um caso à parte, ao qual retorno no próximo parágrafo com a ajuda de um especialista. Todos os três (por ora estou excluindo Husserl) estavam corretos ao caracterizar a ciência do seu tempo da forma como o fizeram, mas que lição há para ser extraída dessa correta caracterização? A de que a ciência estava atravessando uma "crise de legitimidade"? A de que a ciência contemporânea desfruta de uma autoridade que não merece? Essa parece ter sido a lição tirada por eles. Em que a ciência descrita pelos três nas décadas de 1920 e 1930 difere da descrita por Bachelard e Kuhn nas décadas de 1950 e 1960 ? Receio que em nada. Então, por que os mesmos atributos da ciência que eram antes vistos como um sinal de degeneração passaram a ser vistos como um sinal natural de evolução? Minha resposta é: porque a ciência que Ortega y Gasset, Jaspers e Huizinga deploravam era simplesmente a ciência tal como veio a se afigurar no século xx; era a ciência que havia se tornado intrinsecamente difícil e, ao mesmo tempo, cada vez mais dependente da atuação dos especialistas. Para o bem ou para o mal, não existia outra. Não, pelo menos, nesse mundo sublunar em que vivemos.

No que se refere a Husserl, a desilusão com a ciência era de outra natureza. Conforme esclarece Emiliano Trizio, de acordo com Husserl, a crise das ciências europeias

\section{[...] consistia no fato de o dominio especifico do ser que elas tomavam como objeto ter se tornado enigmático. Em termos fenomenológicos, consistia na falta de clareza no que se refere ao sentido da sua verdade e ao sentido do ser que elas investigam. Sem a elucidação desse sentido, elas deixam de ser episteme, isto é, o conhecimento científico do que é em si (Trizio, 2016, p. 205, ênfases no original).}

Trata-se, como se pode notar, de uma "crise da ciência" que só pode existir nos termos do sistema filosófico que Husserl concebeu. Ela só pode ser visível para quem previamente concede que existem um "sentido da verdade" da ciência e um "sentido do ser" que a ciência investiga, ambos à espera de uma "elucidação" que só estará ao alcance de quem já fez a referida concessão prévia. A linha de raciocínio exposta na citação acima foi aplicada para postular a existência de uma crise da física. Em que consistia essa crise? Respondo valendo-me, mais uma vez, da ajuda especializada de Emiliano Trizio:

A cegueira de Galileu para o verdadeiro sentido ("real sense”) da matematização como uma objetivação metódica da natureza pré-científica esculpida no mundo da vida tornou impossível, durante séculos, compreender o sentido do ser ("sense of the being") que é determinado 
pela teoria física e, assim, o sentido de verdade ("truth-sense") desta última. É esta a crise da física $^{1}$ (Trizio, 2016, pp. 208-209).

De acordo com esse excerto, a "crise da física” postulada por Husserl só pode ser visível para quem admite de antemão que: 1) existe mesmo um "verdadeiro sentido" da matematização que estava na base da astronomia de Galileu; 2) esse "verdadeiro sentido" é a "objetivação metódica da natureza pré-científica esculpida no mundo da vida" (o que quer que isso possa significar); 3 ) existe um "sentido do ser", investigado pela "teoria física", a ser devidamente "elucidado"; 4) a teoria física tem um "sentido de verdade" também a ser elucidado; e 5) tanto o "sentido do ser" que a física investiga, quanto o seu "sentido de verdade" tiveram que esperar pelo advento do pensamento filosófico de Husserl para que pudessem ser devidamente elucidados. Uma vez concedido tudo isso, a conclusão a ser extraída é a de que a física esteve "em crise" durante todo o período (que durou quatro séculos, de Galileu a Husserl, se estou compreendendo bem) em que a "cegueira de Galileu" para o "verdadeiro sentido" da matematização que estava na base da sua própria astronomia nos privou de compreender tanto o "sentido do ser" que a "teoria física" investiga quanto o "sentido de verdade" desta última. Não consegui compreender como foi sanada a tripla incompreensão a que Trizio se refere (a do "verdadeiro sentido", a do "sentido do ser" e a do "sentido de verdade"), mas entendi que, de todos os itens listados acima, o único que pode ser discutido sem que se aceitem de antemão as idiossincrasias do sistema filosófico de Husserl é o item 2 e, por essa razão, este é o único item sobre o qual vou me manifestar. Eu teria duas perguntas. Primeira: concedendo-se que a "objetivação metódica" a que esse item se refere é de fato o "verdadeiro sentido" da matematização que estava na base da astronomia de Galileu, trata-se de um "verdadeiro sentido" feito sob medida, ou de um "verdadeiro sentido" prêt-à-porter; isto é, a referida "objetivação metódica”, seja lá o que isso possa significar, é o "verdadeiro sentido" apenas da matematização que se encontra na base da astronomia de Galileu (como o postula Husserl), ou é um "verdadeiro sentido" que pode ser prontamente atribuído à matematização que se encontra na base de qualquer ciência que não tenha perdido seu vínculo com a "natureza pré-científica esculpida no mundo da vida”, o que incluiria não só a astronomia de Galileu, mas também a astronomia de Kepler²,

1. Penso que é recomendável reproduzir o texto original neste caso: "Galileo’s blindness to the real sense of mathematization as a methodic objectivation of the prescientific nature carved out of the life-world has made it impossible, for centuries, to understand the sense of the being that is determined by physical theory, and, thus, the truth-sense of the latter. This is the crisis of physics".

2. Para uma discussão a respeito da matematização que se encontra na base da astronomia de Kepler, ver o trabalho de Anastasia G. Itokazu (Itokazu, 2008). 
a física de Newton $^{3}$ e muitas outras ciências? Segunda pergunta: visto que a física relativística, a mecânica quântica moderna e a química contemporânea contrariam o bom senso, a intuição imediata e, por isso mesmo, não têm qualquer vínculo com a "natureza pré-científica esculpida no mundo da vida" (sendo, a propósito, intrinsecamente difíceis exatamente por essa razão), devemos concluir que todas essas ciências estão em crise e assim permanecerão enquanto não forem devidamente "esclarecidos" o "verdadeiro sentido" da matematização que as sustenta e o "sentido do ser" que cada uma delas investiga? Se a resposta for "sim" (na verdade, não vejo como poderia ser "não"), receio que as ciências contemporâneas precisarão esperar por um novo Husserl para que possam deixar de estar em crise.

É o bastante para o lugar celestial da "crise da ciência", este em que a legitimidade da ciência estará permanentemente em questão enquanto a ciência for esta que conhecemos (a única, a propósito, que existe no mundo sublunar em que vivemos); esta que não tem "clareza" a respeito do "sentido da sua verdade" nem do "sentido do ser" que investiga; que se mantém afastada de tudo o que só pode ser expresso e compreendido de modo intuitivo e nos termos do pensamento cotidiano e, como cereja da torta, que "dá abrigo" a especialistas "formidavelmente medíocres". Passemos, então, aos lugares não celestiais.

Na seção 3, detenho-me na "crise de legitimidade da ciência" que existe no mundo dos sonhos de Feyerabend, um mundo no qual a ciência não desfrutaria dos privilégios de que desfruta no mundo em que vivemos; e, na seção 4, na "crise" que existe nos escritos de cientistas que se viram forçados a se adaptar a um meio que subitamente se tornou abertamente hostil à ciência. Na medida em que a "crise" que existe nesses escritos não exprime uma desilusão pessoal com a ciência (como nos casos de Ortega y Gasset, Jaspers e Huizinga), nem as idiossincrasias de um sistema filosófico (como no caso de Husserl), nem as consequências funestas de uma bem-intencionada utopia libertária (como no caso de Feyerabend), mas um esforço no sentido de melhorar a imagem pública da ciência em um contexto social determinado, é possível dizer que a "crise" que "existe" nos referidos escritos existia, também, no lugar em que estes foram produzidos: a Alemanha da República de Weimar.

Antes de prosseguir, uma palavra sobre as seções 2 e 5 . Na seção 2 ocupo-me de fenômenos que se fazem passar por "crise de legitimidade da ciência" sem sê-lo. Sem esse prévio esclarecimento poderia soar excêntrica a minha tese de que só existem três lugares para a crise de legitimidade da ciência, dois dos quais imaginários e, portanto, de que existe um lugar só: a Alemanha da República de Weimar. Na seção 5, concluo.

3. Para uma discussão sobre a matematização que se está na base da física de Newton, ver o trabalho de Peter Kroes (Kroes, 1998). 
"Crise de legitimidade da ciência" é um fenômeno que não deve ser confundido com dois outros que, embora possam estar circunstancialmente relacionados com a ciência, não têm qualquer conexão necessária com ela. Por falta de melhor nome, vou chamar o primeiro de "a predisposição humana para conceber e acolher teorias conspiratórias e histórias mirabolantes". Ferreira Gullar disse uma vez que a arte existe porque a vida não basta. Penso que não só a arte, mas teorias conspiratórias e histórias mirabolantes também. Ilustro com um exemplo. Em 20 de julho de 1969, o mundo parou para ver, pela televisão, um astronauta pisar no solo lunar. Eu era ainda criança, mas lembro-me bem do ceticismo generalizado em relação ao acontecimento na pequenina cidade do interior de Minas Gerais onde eu estava naquele dia. Houve quem dissesse que aquela "lua" era, na verdade, a vizinha cidade de São Gonçalo do Rio Preto. Como explicar isso? Baixa escolaridade? Tenho uma hipótese alternativa: muito mais empolgante do que ver, pela televisão, um homem descendo de uma nave e pisando no solo lunar é imaginar uma trama fantástica que culmina com a imagem televisiva de um homem descendo de uma nave cenográfica em um lugar misterioso que a um incauto pudesse parecer ser a lua. Se, naquela época, existissem as facilidades que a internet proporciona hoje, incontáveis grupos virtuais se formariam no mundo inteiro para negar o acontecimento. "Crise da ciência"? Não. Simplesmente o anseio por uma vida recheada de mistérios e bizarrices que somente as teorias conspiratórias e as histórias mirabolantes podem proporcionar. Não importa, nesse caso, o que vem a ser negado por essas "teorias" e histórias. Relatei um caso no qual se negou a ocorrência de um feito extraordinário da ciência e da tecnologia, mas qualquer fato sem qualquer conexão com a ciência pode ser igualmente negado. Um exemplo pitoresco: a morte do cantor Michael Jackson. Não faltaram histórias mirabolantes para negar esse acontecimento.

Isso dito, devo mencionar que o ato de negar o que não há como ser negado, por meio de teorias conspiratórias e histórias mirabolantes, faz muito mais do que meramente satisfazer o anseio por uma vida mais recheada de mistérios e bizarrices. Esse ato pode estabelecer laços sociais duradouros com uma eficiência que as afirmações cujas validades estão acima de qualquer dúvida razoável jamais seriam capazes de estabelecer. Isso não é difícil de ser demonstrado. Basta que se compare a eficiência de afirmações razoáveis e a de afirmações estapafúrdias no que se refere às suas respectivas capacidades de criar laços sociais. Tomemos, por exemplo, as seguintes afirmações: "A Terra é esférica mas achatada nos polos" e "A Terra é plana". Qual delas pode criar laços sociais e mantê-los estreitos? Evidentemente a segunda. Quem acredita que a Terra é plana faz parte de um grupo especial, de uma verdadeira "comunidade", 
mantida por meio da reafirmação periódica da crença no formato plano do planeta; mas quem acredita que a Terra é geoide (isto é, esférica mas achatada nos polos) não faz parte de comunidade alguma. Existem bilhões de pessoas no mundo - entre as quais estou incluído e, suponho, também o leitor - que compartilham a crença de que nosso planeta tem o formato de uma esfera, sem que exista um único "esferista". Em contrapartida, quem quer que compartilhe a crença no formato plano do planeta é um “terraplanista”. Da mesma forma, existem bilhões de pessoas que afirmam que estamos vivendo uma pandemia, que aglomerações provocam contágio e que vacinas imunizam, sem que exista um único "afirmacionista”. Para aqueles que negam tudo isso, em contrapartida, existe um nome bastante conhecido: "negacionistas". O fato de existirem "negacionistas" da ciência, por mais numerosos e ruidosos que possam ser, não é, entretanto, um indicador da existência de alguma “crise da ciência”, por razões que se mostrarão claras na seção 4. Por ora é suficiente mencionar que, para que se possa falar propriamente de crise de legitimidade da ciência nesse caso, seria necessário que os negacionistas se mostrassem capazes de criar um ambiente de hostilidade à ciência ao qual os cientistas tivessem que reagir de alguma forma para se acomodar a esse ambiente.

Um segundo fenômeno que pode parecer característico de uma "crise da ciência" sem sê-lo é a busca de solução, fora da ciência, para problemas que supostamente deveriam ser resolvidos apenas com a ajuda da ciência. Esse fenômeno exprime um desacordo entre aquilo que o conhecimento científico postula ser a verdade e aquilo que certos grupos ou pessoas gostariam que, em determinadas circunstâncias, fosse a verdade. Se, por exemplo, os químicos postulam que um determinado componente químico é prejudicial aos lençóis freáticos, aqueles que fabricam e utilizam os produtos que contêm esse componente tenderão a protestar. Suponhamos que o protesto seja bem-sucedido e, em razão desse sucesso, não haja restrição legal ao uso de produtos que contenham o referido componente. Suponhamos, também, que desacordos com desfechos dessa natureza se generalizem. Isso configuraria uma "crise de legitimidade da ciência”? Se alguém quiser responder que sim, não vou brigar por causa disso, mas, conforme pretendo deixar claro na seção 4, para que ocorra, a rigor, uma crise de legitimidade da ciência é necessário existir um ambiente hostil à atividade científica ao qual os cientistas que atuam nesse ambiente precisam reagir de alguma forma. No caso hipotético relatado acima não há hostilidade à ciência; esta só existiria se as alegações de conhecimento dos nossos hipotéticos químicos pudessem ser rechaçadas, com alguma chance de êxito, não sob o argumento de que há erros na cadeia de raciocínio ou na investigação que os conduziu à conclusão a que chegaram, como usualmente acontece, mas sob o argumento de que nada há de especial em relação ao conhecimento científico para que uma alegação de conhecimento vinda de um quí- 
mico mereça alguma atenção especial. Nesse caso, só seria apropriado falar em crise de legitimidade da ciência, com ou sem aspas, se o ambiente social em que atuam nossos hipotéticos químicos fosse de tal forma hostil à ciência que os fabricantes dos referidos produtos pudessem, com chance de êxito, aduzir em favor de si o argumento de que a ciência é apenas uma forma de conhecimento entre outras possíveis, a começar pelo "saber tradicional" daqueles que lidam cotidianamente com produtos químicos e, por conseguinte, que não há razão para conceder algum crédito especial a um parecer formulado com base na química. Presumo que no mundo em que vivemos não há chance de uma alegação de tal natureza receber algum acolhimento institucional e, não havendo essa chance, os químicos não precisam redefinir os rumos que a química precisa tomar para que esta não fique vulnerável à alegação de que a química não é um corpo de conhecimento particularmente qualificado para emitir juízo sobre os impactos ambientais de um determinado composto químico. Mas, no mundo em que Feyerabend gostaria de ter vivido, uma alegação de tal natureza teria plenas chances de êxito. Por essa razão, esse mundo é um lugar em que uma crise de legitimidade de ciência, sem aspas, poderia ter uma vida longa e próspera.

No capítulo final de Contra o método, cuja primeira edição em inglês data de 1975, Feyerabend descreve o mundo dos seus sonhos: "uma sociedade livre, onde cada qual deve ter a possibilidade de decidir por si próprio e de viver de acordo com as crenças sociais que tenha por mais aceitáveis" (Feyerabend, 1985, p. 454, ênfases acrescentadas). Nota-se que a frase está incompleta. Feyerabend gostaria de viver em uma sociedade onde cada qual pudesse "decidir por si próprio". Decidir, por si próprio, sobre o quê? A resposta está nesta passagem:

\footnotetext{
Quase todos os assuntos científicos são matérias obrigatórias em nossas escolas. Se os pais de uma criança de seis anos podem decidir se ela receberá rudimentos de protestantismo ou de judaísmo ou se não terá instrução religiosa alguma, não gozam esses pais da mesma liberdade no que respeita à ciência. Física, Astronomia, História devem ser estudadas. Não podem ser substituídas por mágica, astrologia ou por um estudo das lendas (Feyerabend, 1985, p. 456).
}

No mundo em que Feyerabend gostaria de ter vivido, seria uma incumbência sobretudo dos pais das crianças decidirem sobre o conteúdo a ser ensinado a elas nas escolas, e a decisão deveria ser tomada com base nas "crenças sociais" que considerassem as "mais aceitáveis". Uma proposta de tal natureza só faz sentido na medida em que se presume a validade de dois pressupostos. O primeiro é o de que a ciência 
é apenas uma "crença social" entre tantas outras que a ela equivalem de um ponto de vista epistemológico. $\mathrm{O}$ segundo diz respeito a um problema de ordem operacional. Suponhamos que uma determinada escola tenha trezentos alunos, todos com os pais vivos. Suponhamos também, para simplificar, que não há divergência de opinião entre o pai e a mãe (ou entre os dois pais ou as duas mães, no caso de casais homoafetivos) de cada aluno, de modo a podermos considerar cada casal uma única pessoa. Seriam, assim, cento e cinquenta pessoas, todas pretendendo que seja ensinado ao filho aquilo que cada uma tem na conta de "crença social mais aceitável". Como viabilizar uma demanda de tal natureza? Há duas possibilidades: ou as cento e cinquenta pessoas convergem no que se refere às "crenças sociais" que têm por mais "aceitáveis", ou a escola é "pluralista" a ponto de poder acolher crianças cujos pais têm as mais diferentes posições a respeito de quais "crenças sociais" são as "mais aceitáveis". No primeiro caso, rege o pressuposto de que a sociedade precisa ser segmentada em grupos formados por pessoas que tenham por "mais aceitável" o mesmo conjunto de "crenças sociais". Visto que "crenças sociais" tais como a de que dois mais dois são quatro, a terra é geoide, fornos crematórios existiram e vacinas imunizam não são eficientes para a criação de laços sociais, os grupos se formariam a partir do compartilhamento de "crenças sociais" de outra natureza. Que grupos se formariam nessas circunstâncias? Eis algumas possibilidades: negacionistas de toda sorte, criacionistas, supremacistas raciais e "masculinistas". $\mathrm{Na}$ "sociedade livre" em que Feyerabend gostaria de ter vivido, os pais que fizessem parte de grupos como esses teriam que ser livres para decidir sobre o que deveria ser ensinado aos seus filhos. Quanto ao segundo caso, aquele que diz respeito à criação de escolas suficientemente "pluralistas", neste rege o pressuposto de que não há limites para a cognição humana. Com efeito, se uma determinada escola admite o ingresso de um aluno cujos pais têm "por mais aceitável" a crença em, digamos, orixás, todas as crianças teriam que aprender sobre o conhecimento embutido nessa crença, o mesmo se aplicando se a crença em alta conta for em vodu ou no que mais possa ser. Feyerabend menciona que nos Estados Unidos houve progresso nessa direção, não obstante:

[...] a ciência continua a reinar soberana. Reina soberana porque seus praticantes são incapazes de compreender e não se dispõem a tolerar ideologias diferentes, porque têm força para impor seus desejos e porque usam essa força como seus ancestrais usaram a força de que dispunham para impor o cristianismo aos povos que iam encontrando em suas conquistas. Assim, embora um norte-americano possa, agora, abraçar a religião do seu gosto, não lhe é

4. O “masculinismo" foi um tema tratado por Lenin Bicudo Bárbara em sua tese de doutorado (Bárbara, 2018). 
permitido pedir que, na escola, seus filhos aprendam mágica e não a ciência (Feyerabend, 1985, p. 453, ênfases no original).

Segundo Feyerabend, só há um meio de superar esse deplorável estado de coisas: manter o Estado separado da ciência da mesma forma que já se acha separado da Igreja. Afinal, não há razão alguma para que se conceda algum crédito especial à ciência:

[...] a ciência não tem autoridade maior que a de qualquer outra forma de vida. Seus objetivos não são, por certo, mais importantes que os propósitos orientadores de uma comunidade religiosa ou de uma tribo que se mantém unida graças a um mito. De qualquer modo, não há por que esses objetivos possam restringir as vidas, os pensamentos, a educação dos integrantes de uma sociedade livre, onde cada qual deve ter a possibilidade de decidir por si próprio e de viver de acordo com as crenças sociais que tenha por mais aceitáveis. A separação entre Estado e Igreja deve, portanto, ser complementada pela separação entre Estado e ciência (Feyerabend, 1985, p. 454).

Uma vez efetuada essa separação, o Estado não teria mais por que "gastar somas imensas" no "desenvolvimento de ideias científicas" (Feyerabend, 1985, p. 455). Feyerabend arremata essa linha de raciocínio argumentando que a ciência não precisa do Estado, porque "sempre haverá pessoas que preferirão ser cientistas a ser donos de seus destinos e que se submeterão alegremente à mais desprezível forma de escravidão (intelectual e institucional) contanto que se vejam bem pagas e que tenham em torno de si quem lhes examine o trabalho e lhes cante louvores" (Feyerabend, 1985, p. 454).

Há uma dose considerável de verdade não trivial na afirmação de que dedicar-se à ciência é submeter-se alegremente a imposições tirânicas de ordem intelectual e institucional em troca de "ter em torno de si" quem possa examinar o trabalho feito e, se possível, elogiá-lo. Mas, na sociedade livre em que Feyerabend gostaria de ter vivido, não pode existir lugar para imposições tirânicas de natureza alguma (embora, conforme veremos, acaba havendo, sim, uma imposição bastante tirânica). A ciência não pode ser uma exceção. Ao explicar por que não, Feyerabend nos provê a descrição de um quadro hipotético de hostilidade à ciência:

A maneira como aceitamos ou rejeitamos ideias científicas é radicalmente diversa dos processos de decisão democrática. Aceitamos leis científicas e fatos científicos, ensinamo-los nas escolas, tornamo-los a base de importantes decisões políticas, sem, contudo, havê-los submetido à votação. Os cientistas não os submetem a votação - ou, pelo menos, assim dizem proceder - e os leigos por certo não os submetem a voto. Propostas concretas [nos parlamentos] são, por 
vezes, objeto de debate e sugere-se votação. Todavia, o processo não se aplica a teorias gerais e a fatos científicos. A sociedade moderna é "copernicana”, mas não porque a doutrina de Copérnico haja sido posta em prática, submetida a um debate democrático e então aprovada por maioria simples; é "copernicana" porque lhe aceitamos a cosmologia tão acriticamente quanto, no passado, se aceitou a cosmologia de bispos e cardeais (Feyerabend, 1985, p. 456).

Quando os cientistas exercem suas atividades em ambientes nos quais objeções dessa natureza seriam apenas um alvo fácil de galhofas, não há crise da ciência. Mas, se não é este o caso; se o exercício da atividade científica se dá em um ambiente em que objeções como essas precisam ser levadas a sério pelos próprios cientistas; em um ambiente hostil à ciência a ponto de requerer dos cientistas uma reconstrução a partir do zero de suas respectivas disciplinas ou especialidades para confrontar alegações como as acima, aí, sim, estaríamos diante de uma crise da ciência. E à imaginação de Feyerabend não faltaram alegações que pudessem concorrer para o agravamento do quadro hipotético de hostilidade à ciência contido na citação acima. Vejamos, por exemplo, esta alegação: "enquanto uma democracia faz algum esforço para esclarecer o processo, de sorte que todos o entendam, a ciência ou o esconde ou o distorce, para que se amolde a seus sectários interesses" (Feyerabend, p. 457, ênfase no original).

Certamente Feyerabend não está se referindo à ciência do seu próprio tempo, mas à ciência de um tempo em que o conhecimento comum podia assimilar de forma gradativa o conhecimento científico a ponto de, por exemplo, o conhecimento de física que o próprio Newton tinha não ser superior ao de um professor de física de ensino médio do nosso tempo. A ciência do próprio tempo de Feyerabend não é esta, mas é aquela que, conforme foi dito no primeiro parágrafo do presente ensaio, tornou-se difícil em si, impermeável ao conhecimento comum e, por isso mesmo, mais do que nunca na mira do escrutínio crítico especializado, como mostra esplendidamente esta passagem do já citado livro de Bachelard, publicado em 1953:

Ao ler um livro como o de Gamov e Critchfield sobre a física nuclear, vê-se até que ponto os cientistas têm consciência da imperfeição dos seus métodos. "Não satisfaz", eis uma locução repetida em quase todos os parágrafos [ênfases acrescentadas]. Nunca este racionalismo experimentado [ênfase no original], que os métodos novos representam, foi mais variado, mais móvel, mais vigiado (Bachelard, 1990, p. 247).

Trata-se, conforme se vê, de um quadro bem distinto daquele que foi descrito por Feyerabend cerca de vinte anos mais tarde. Neste último, os cientistas podem ter tamanha segurança a respeito da pertinência de suas conclusões e tamanho domínio do "processo" que os conduz a elas que até se dão ao luxo de "distorcer" ou 
"esconder" o que fazem. Por exemplo, eles podem estar tão seguros de que a teoria heliocêntrica não é intrinsecamente melhor do que a geocêntrica que podem até se dar ao luxo de apresentar a primeira como se o fosse, recorrendo, para tanto, ao expediente de "esconder" ou "deturpar" o conhecimento absolutamente seguro que, nesse caso, teriam a respeito dos méritos e deméritos intrínsecos de cada uma dessas teorias. Na ciência contemporânea simplesmente não é possível existir uma segurança de tal natureza porque não há como ter domínio do processo que poderia conduzir a conclusões inequívocas, conforme transparece na citação de Bachelard acima, especialmente no trecho em que se lê: "Não satisfaz", eis uma locução repetida em quase todos os parágrafos". Isso nos traz de volta à velha tecla: não existe mais a continuidade entre o conhecimento científico e o conhecimento comum que Feyerabend obstinadamente insistia em afirmar que existe. Bachelard registrou essa descontinuidade nos seguintes termos:

E eis aqui uma descontinuidade que não será fácil de apagar invocando um simples relativismo: de fácil, a química torna-se, subitamente, difícil. Torna-se difícil não só para nós próprios, difícil não só para o filósofo, mas verdadeiramente difícil em si. Os historiadores da ciência não aceitarão que se caracterize a cultura científica do nosso tempo como especificamente difícil. Objetarão que, ao longo da história, todos os progressos foram difíceis, e os filósofos repetirão que os nossos filhos aprendem hoje na escola com facilidade aquilo que exigiu um esforço extraordinário aos gênios solitários dos tempos passados. Mas este relativismo, que é real, que é evidente, mais não faz do que salientar melhor o caráter absoluto da dificuldade das ciências físicas e químicas contemporâneas, a partir do momento em que se sai do reino da elementaridade (Bachelard, 1990, pp. 247-248, ênfases no original).

Mencionei anteriormente que a "sociedade livre" em que Feyerabend gostaria de ter vivido não está a salvo de imposições tirânicas. Pois é chegado o momento de dizer de que imposição tirânica se trata: aos membros dessa sociedade não é facultada a permissão para transpor os limites do "reino da elementaridade". Eles são forçados a se manterem confinados aos limites desse reino. Se Bertrand Russell tivesse sido um membro dessa sociedade, de lá teria sido banido em 1925, ano em que transpôs esses limites ao advertir que a teoria da relatividade só se presta a uma compreensão bastante superficial para quem não é um estudioso do assunto. Bachelard teria sido banido em 1934, ano em que transpôs completamente os limites do reino da elementaridade ao publicar $O$ novo espírito cientifico. Kuhn teria sido banido em 1962, ao publicar A estrutura das revoluções cientificas. Mas, em pleno ano de 1975, Feyerabend insistia em se manter nos limites desse reino porque, se não o fizesse, a sociedade dos seus sonhos poderia esfumar-se. Ele precisou, então, caracterizar o 
espírito científico como "um espírito canalizado no dogmatismo de uma verdade indiscutida" (valho-me, aqui, de uma expressão bastante feliz de Bachelard [1990, p. 247]) para ter sua bête noire. Essa besta precisaria ser domada a todo custo, e o modo de fazê-lo seria mantê-la apartada do Estado. Sem a tutela do Estado, ela perderia seus dois privilégios: a obrigatoriedade de sua presença nos currículos escolares e o financiamento público. Eis, então, o que seria da ciência no mundo dos sonhos de Feyerabend: uma "crença social” que precisaria permanentemente redefinir seus rumos para poder ajustar-se a um ambiente que pressupõe a existência de inúmeros grupos, articulados em torno das mais diferentes “crenças sociais", em permanente disputa por espaço institucional! É possível imaginar um quadro de "crise da ciência" mais inequívoco do que este? Pois é este o quadro a que seríamos conduzidos em uma sociedade na qual se é livre para tudo desde que não se transponham os limites do "reino da elementaridade". Entretanto, também é possível existir um quadro de crise de legitimidade da ciência na vida real, isto é, em sociedades nas quais não há esse tipo de restrição. É o caso da Alemanha da República de Weimar. Se há mais algum, desconheço.

Entre 1918 e 1933, mais de 370 livros foram publicados na Alemanha tendo o termo "crise" no título. A incidência desse termo permaneceu constante nos dez primeiros anos, deu um salto em 1928 e outro no biênio 1931-32 (Graf, 2010, p. 592). O salto não foi apenas no que diz respeito ao número de livros, mas, sobretudo, ao leque de adjetivos que passaram a qualificar o substantivo "crise". Assim, em 1920 só havia “crise econômica”, porém, em 1930, havia crise "econômica”, "política”, "moral”, "religiosa”, “cultural”, “revolucionária”, "financeira”, “industrial”, “da agricultura”, "do capitalismo", "da Alemanha" e, para coroar tudo isso, a "crise mundial” (Graf, 2010, pp. 592-593). Nota-se que, nessa lista, falta a “crise da ciência”. É possível que essa expressão só tenha aparecido no título de um livro em 1936, com a publicação de $A$ crise das ciências europeias e a filosofia transcendental, mas, muito antes de Husserl ter publicado esse livro, os mais destacados matemáticos e físicos alemães do período do entreguerras jamais se descuidaram da "crise da ciência". Assim, logo nos primeiros anos que se seguiram à humilhante derrota, 1919 ou 1920, o matemático Hermann Weyl proclamou, quase que do nada, a existência de uma crise nos fundamentos da matemática (Forman, 1971, p. 62). ${ }^{5}$ Com extraordinária rapidez,

5. Em 1921 esse matemático publicou um livro hoje disponível, em inglês, sob o título On the new foundational crisis of mathematics. 
relata Forman, a comunidade matemática alemã começou a sentir o quanto eram inseguros os fundamentos sobre os quais se erguia toda a estrutura da análise matemática e quão duvidosos eram os métodos utilizados para construir o edifício do conhecimento matemático (Forman, 1971, p. 60). Forman enfatiza que um número considerável de matemáticos alemães exigiu, com um "entusiasmo quase-religioso", uma reconstrução completa da matemática; uma redefinição radical dos caminhos a serem tomados, a qual, muito apropriadamente, era chamada de "intuicionismo" (Forman, 1971, p. 60). No que se refere à física, o quadro era o mesmo. Nesse caso, o tema era a "crise da velha teoria quântica" que atingira os físicos atômicos (principalmente os alemães) nos anos anteriores à introdução da mecânica quântica, em 1925/26. Considerando apenas os casos em que o termo "crise" aparece nos títulos dos trabalhos nesse período, cabe mencionar a conferência de Richard von Mise, "On the present crisis in Mechanics", proferida em setembro de 1921, e a brochura de Johannes Stark "The present crisis in German Physics", publicada em junho de 1922, seguida dos comentários de Joseph Petzoldt "Concerning the crisis of the causality concept", em julho de 1922; e, em agosto desse mesmo ano, Albert Einstein, isso mesmo, Albert Einstein, publicou um artigo popular intitulado "On the present crisis in Theoretical Physics" (Forman, 1971, p. 60). Nenhuma dessas publicações exprimia alguma desilusão com o modo como o conhecimento científico havia se desenvolvido até então, nem, muito menos, prenunciava o advento de tempos sombrios para a ciência, como o fariam, poucos anos mais tarde, Ortega y Gasset, Jaspers e Huizinga. Tratava-se, antes, do oposto:

\footnotetext{
Grosseiramente falando, cada um desses físicos está apontando na mesma direção - a teoria quântica. Mas, aqui, o acordo termina, pois cada um está colocando o dedo sobre um "problema” completamente diferente. Contudo, essa mesma circunstância, a aplicação generalizada mas, ao mesmo tempo, muito mal focada da palavra e noção de crise sugere que a crise da velha teoria quântica, longe de ser um fardo para os físicos alemães, era mais do que bem-vinda para eles (Forman, 1971, pp. 62-63).
}

Eis, então, o quadro que Forman nos oferece: uma aplicação generalizada, mas, ao mesmo tempo, muito mal focada da noção de "crise da ciência". Na verdade, nada há de surpreendente nisso (e Forman bem o sabia), se tivermos em conta este quadro mais geral, descrito por Fritz Ringer:

Ao longo do período de Weimar era dito frequentemente nos círculos acadêmicos que uma crise estava acontecendo. Ninguém sentia a necessidade de definir exatamente qual era a natureza da crise, de perguntar de onde ela veio e o que a sua existência implicava. 
"Algumas vezes [escreveu o educador Aloys Fischer, em 1924] a situação presente era representada como uma crise do [...] sistema econômico apenas, algumas vezes como uma crise política e da própria ideia de estado ou da ordem social. Em outros, era concebida de forma mais profunda como uma crise de toda a cultura intelectual e espiritual, uma crise da consciência religiosa [...] do Ocidente". De qualquer forma, a crise existia, nem que fosse pelo simples fato de quase todos os alemães escolarizados acreditarem em sua existência (Ringer, 1969, p. 245).

Na verdade, na Alemanha desse período havia mais do que a disseminação generalizada de uma ideia de crise sem que se soubesse exatamente o que essa palavra significava. Havia, como bem o disse o historiador Rüdiger Graf, uma "quase-competição" entre as mais eminentes vozes que então se posicionavam ideologicamente para determinar quem seria capaz de descrever a crise em termos os mais abrangentes e fundamentais possíveis (Graf, 2010, p. 608). Hans von Henting, um dos mais importantes psicólogos criminais do seu tempo, e o filósofo Arthur Liebert, autor de uma vastíssima e influente obra, saíram na frente; Henting, ao publicar, em 1920, o livro Über den Zusammenhan von kosmischen, biologishen und sozialen Krisen [Sobre a conexão entre as crises cósmica, biológica e social], e Liebert, ao publicar, em 1921, Die geistige Crisis der Gegenwart [A crise espiritual do presente]. Nos escritos do primeiro, a crise aparecia como um fenômeno que tinha afetado toda a vida política, social e econômica, não apenas na Alemanha, mas, também, no Ocidente e em todo o mundo (Graf, 2010, p. 608). Liebert, por sua vez, tentou encontrar "a crise" do seu tempo que pairava além de todas as crises particulares e servia como a fonte espiritual e metafísica de todas elas (Graf, 2010, p. 608). Richard N. Coudenhove-Kalergi, a quem se credita a primeira formulação de um projeto moderno de unificação da Europa, não podia ficar de fora dessa disputa. Em 1923, publicou um livro intitulado Krise der Weltanschauung, no qual retomava a tese, defendida por Henting, de que de tempos em tempos todo o mundo se defronta com uma crise sem precedentes. De acordo com ele, aquele era um momento em que ocorria uma dupla crise, política e ética, jamais vista desde os tempos primevos. Em 1926, era a vez de a feminista liberal Gertrud Bäumer postular a existência de uma conexão entre as crises ocupacional, sexual e espiritual ao publicar o livro Die Frau in der Krisis der Kultur [A mulher na crise da cultura]. Nesse mesmo espírito, em 1928, o político Edgard Julius Jung, líder de um movimento revolucionário conservador que se opunha tanto à República de Weimar quantos ao então nascente movimento nazista, e cujos escritos eram publicados em Die Deutsche Rundschau, o mais importante periódico político e literário na época, buscava estabelecer a conexão entre as "crises religiosa, cultural, judicial e do estado" (Graf, 2010, p. 608). 
Do exposto transparece o quanto a Alemanha da República de Weimar era uma sociedade "ávida por crises", para falar como Paul Forman (Forman, 1971, p. 58). Nessas circunstâncias, uma atividade social que não estivesse "em crise", ou que pelo menos não pudesse apresentar-se dessa forma, seria um alvo em potencial de hostilidades. Foi o que aconteceu às ciências exatas na Alemanha. Estas se tornaram um alvo aberto de hostilidades da noite para o dia, ou, para ser literal, do verão de 1918 para o outono desse mesmo ano. No verão, havia um sentimento generalizado de que a Alemanha estava a caminho da vitória e, no rastro desse otimismo, os cientistas alemães chamavam a atenção para a grande importância prática que a física, a química e a matemática estavam tendo durante a guerra e a conveniência e inevitabilidade de uma colaboração ainda mais estreita com a tecnologia no futuro (Forman, 1971, p. 8). Sentiam-se, nessa ocasião, seguros de que teriam pela frente institutos de pesquisa ainda maiores, mais bem equipados e em maior número, como também um aumento substancial de estima pública e prestígio acadêmico. No outono, esse castelo de cartas ruiu. Com a derrota alemã, uma escala de valores radicalmente nova se colocou diante dos homens de ciência que no verão anterior ainda podiam desfrutar da mais elevada estima. Nos marcos dessa nova escala, as ciências exatas passaram a ocupar uma posição muito baixa (Forman, 1971, p. 9). Assim é que, em 1927, o periódico Süddeutsche Monatshefte, um dos mais bem conceituados veículos de divulgação cultural e científica daquela época, atendeu aos apelos feitos por Feyerabend em 1975 e se permitiu dedicar um número especial à astrologia. Dentre os cientistas convidados a contribuir, destacava-se um nome: Arnold Sommerfeld, um dos maiores físicos teóricos do seu tempo. Sommerfeld aceitou o convite, mas não escondeu sua indignação: "Não parece um anacronismo monstruoso que no século Xx um periódico respeitado se vê obrigado a solicitar uma discussão sobre astrologia? Que círculos mais amplos do público instruído ou meio instruído são mais atraídos pela astrologia do que pela astronomia?" (Forman, 1971, p. 13). Esse ato de elevar a astrologia à condição de ciência era, para Sommerfeld, um claro indicador de que a Alemanha estava "mais uma vez mergulhada em uma onda de irracionalidade e romantismo como aquela que há cem anos se espalhara pela Europa como uma reação ao racionalismo do século XVIII e sua tendência a tornar a solução do enigma do universo demasiadamente fácil” (Forman, 1971, p. 13). São muitos os contemporâneos de Sommerfeld que apontaram para a existência dessa "onda de irracionalidade", mas, para os propósitos da presente discussão, é suficiente reproduzir o depoimento do sociólogo e pedagogo Alfred Vierkandt, que, ao discutir, em 1920, as exigências sociopedagógicas que eram impostas em seu país naquela época, escreveu: 
[...] de modo geral experimentamos, hoje, uma rejeição completa do positivismo; estamos experimentando uma nova necessidade de unidade, uma tendência sintética em todo o mundo do conhecimento (Wissenschaft) - um modo de pensar (Eindenken) que enfatiza primariamente o orgânico em vez do mecânico, o vivo em vez do morto, os conceitos de valor, propósito e finalidade em vez do conceito de causalidade ${ }^{6}$.

Esse "modo de pensar" que "enfatiza primariamente" o "orgânico em vez do mecânico, o vivo em vez do morto, os conceitos de valor, propósito e finalidade em vez do conceito de causalidade" tem nome: Lebensphilosophie (filosofia da vida). Trata-se, digamos assim, de uma variante tardia do romantismo alemão, surgida na Alemanha no fim do século Xıx. Essa variante dominou o meio intelectual alemão durante toda a República de Weimar imprimindo-lhe a sua marca: a rejeição da razão como via de acesso ao conhecimento sob o argumento de que esta é indissociável de uma visão materialista e mecanicista do conhecimento. A razão, diziam, concentra-se na análise de nexos causais e ignora todo o conhecimento a que não se pode ter acesso sem a mediação dessa análise; é uma faculdade que desintegra, em vez de integrar, pois é incapaz de satisfazer a "fome pela unidade" (bunger for wholeness). Sob o seu domínio, estamos impedidos de glorificar a "vida”, a intuição e toda experiência que, a exemplo do arrebatamento instantâneo que uma obra de arte pode causar, não se presta prontamente à reflexão. Em um país arruinado por uma guerra, ideias como essas podem ter um apelo irresistível. E tiveram. Após a derrota alemã, ensina-nos Forman, toda a literatura sobre a Weltanschauung burguesa amplamente lida era alinhada a elas; era tributária da Lebensphilosophie (Forman, 1971, p. 16).

Um mundo como este deixava aos homens de ciência três opções: abandoná-lo (fosse mudando de país ou de profissão), tentar transformá-lo ou tentar adaptar-se a ele. A terceira opção foi a escolhida. No verão de 1923, o físico Max Born, que posteriormente viria a ser laureado com o Prêmio Nobel de Física por sua atuação no desenvolvimento da teoria quântica, exprimiu o sentimento que dominava os físicos alemães dessa época ao declarar que "todo o sistema de conceitos da física precisava ser reconstruído a partir do zero” (Forman, 1971, p. 61-62). A expressão “a partir do zero", nesse contexto, tinha um significado muito preciso: "a começar pela renúncia ao conceito de causalidade". Em um mundo onde tudo estava em crise, até mesmo a sexualidade, que chance de sobrevivência poderia ter uma ciência que também não o estivesse? Pois a renúncia ao conceito de causalidade, o grande vilão aos olhos da

6. Alfred Vierkantdt, Die Sozial Paedagogische Forderumg der Gegenwart, Berlin, 1920, tal como citado por Forman (1971, pp. 16-17), que, por sua vez, reproduziu a citação da tese de doutorado de Fritz Ringer, defendida na Universidade de Harvard, em 1960, sob o título The German universities and the crisis of learning, 1918-1932, p. 145. 
Lebensphilosophie, indicava que agora até mesmo a física estava em crise. Nessa nova condição, ela estaria apta a ganhar posições na escala de valores que passou a vigorar na Alemanha após a derrota na guerra e a subsequente submissão da elite intelectual alemã ao domínio intelectual da Lebensphilosophie.

Anteriormente reproduzi uma passagem dos escritos de Fritz Ringer na qual se lê: "De qualquer forma, a crise existia, nem que fosse pelo simples fato de quase todos os alemães escolarizados acreditarem em sua existência” (Ringer, 1969, p. 245). Presumo que Ringer estivesse sendo irônico. Seja como for, uma "crise da ciência" não existe pelo fato de um número considerável de pessoas acreditar em sua existência nem, tampouco, pelo fato de a ciência vir circunstancialmente a se encontrar em uma situação desoladora, quer por lhe faltarem recursos financeiros, quer por lhe faltar uma boa imagem pública. Para que se possa falar com propriedade em crise da ciência, é necessário que a atividade científica seja conduzida em um ambiente que lhe seja hostil a ponto de lhe impor uma mudança drástica de rumos, tal como, por exemplo, a que consistiu na renúncia, acima mencionada, ao conceito de causalidade. Valho-me da preciosa ajuda do historiador Rüdiger Graf para me fazer entender melhor:

\footnotetext{
Por mais desoladores, desordenados ou turbulentos que sejam os eventos e processos em um determinado momento, eles só constituem uma crise se algum observador os relaciona com um desenvolvimento passado e projeta dois caminhos alternativos no futuro, definindo, dessa forma, o presente como um momento crítico de decisão. Entendida dessa forma, a constituição de uma crise pressupõe um observador, seja um contemporâneo com seus interesses particulares, seja o historiador tentando descrever um ponto de inflexão em sua narrativa (Graf, 2010, pp. 599-600).
}

Em sintonia com o que está dito acima, receio que só seja apropriado falar em "crise de legitimidade da ciência" quando é possível documentar o modo como aqueles que se veem em um ambiente de aberta hostilidade à ciência definem o presente como um momento crítico de decisão e projetam dois caminhos possíveis de serem percorridos, um que conduzirá à adaptação ao ambiente hostil, e outro que não o fará. Nesse sentido, "crise" é uma ideia intrinsecamente conectada à expectativa de algum desenvolvimento futuro (Graf, 2010, p. 600). Ao caracterizar o momento em que viviam como um momento "de crise", os cientistas, intelectuais e políticos da República de Weimar não estavam necessariamente exprimindo um sentimento de mal-estar, mesmo porque, na maior parte das vezes, sequer existia esse sentimento; nem tampouco fazendo um diagnóstico sombrio do próprio tempo, como o fizeram Henting, Liebert e todos aqueles humanistas influentes que, por assim dizer, "competiam" para mostrar qual era a verdadeira "extensão" e "profundidade" da crise em 
que supostamente estavam imersos; eles estavam, sobretudo, definindo o presente como um momento de decisão entre duas alternativas existenciais mutuamente excludentes, de modo a exortar outras pessoas a tomarem a decisão certa (Graf, 2010, p. 614). Nesse sentido, tanto quanto a expectativa de um desenvolvimento futuro, ou, para ser mais preciso, exatamente em razão de pressupor essa expectativa, uma crise pressupõe alguma forma de projeção de alternativas existenciais mutuamente excludentes. Temo que o leitor não terá ideia do que estou falando se eu não exemplificar. Pois o melhor exemplo que encontrei de "projeção de alternativas existenciais mutuamente excludentes” está em uma citação dos escritos de Edmund Husserl. A escolha pode não parecer muito feliz porque Husserl, conforme argumentei anteriormente, diagnosticou uma crise da ciência que só pode "aparecer" para quem já aceita de antemão as idiossincrasias de seu sistema filosófico. Não obstante isso, Husserl revelou-se imbatível no que se refere à tarefa de "projetar alternativas existenciais mutuamente excludentes":

Há duas saídas para a crise da existência europeia: a ruína da Europa ao afastar-se do sentido racional da vida que lhe é próprio; sua queda na barbárie e no ato de hostilizar o espírito, ou o renascimento da Europa a partir do espírito da filosofia através de um heroísmo da razão que supera o naturalismo de uma vez por todas (Husserl, 1970, p. 298, apud Trizio, 2016, p. 193).

Esse tom quase apocalíptico, do tipo "isto ou aquilo", a luz ou as trevas, o renascimento ou a ruína, exemplificado na passagem acima, era bastante disseminado nos escritos da Alemanha da República de Weimar e consistia, por assim dizer, o arremate de todo esforço no sentido de definir o momento presente como um momento crítico de decisão. Na medida em que essa definição convertia o momento presente em uma encruzilhada que apontava para a existência de dois caminhos alternativos, um dos quais conduziria à luz e o outro às trevas, e em que os cientistas se viam impelidos a escolher um deles sem qualquer garantia de que fariam a escolha certa, é possível dizer que a crise não existia apenas nos escritos que declaravam sua existência, mas no próprio lugar em que esses escritos foram produzidos, a Alemanha da República de Weimar.

\section{5}

Presumo que meus estimados colegas que me alegraram e me honraram com o convite para contribuir com a realização deste dossiê têm a expectativa de que eu possa oferecer uma resposta razoável para a seguinte pergunta: existe no momento uma crise de legitimidade da ciência? Desconheço a resposta, mas tenho um palpite 
sobre onde ela pode ser encontrada. Vamos admitir, por hipótese, que vivemos um clima de aberta hostilidade à ciência (pessoalmente não penso que isso seja verdade, mas vamos admitir que seja). Uma vez admitida essa hipótese, há de se indagar: essa hostilidade se manifesta de forma segmentada, episódica, ou de forma sistemática, com a ajuda de concepções filosóficas razoavelmente bem sedimentadas e bem aceitas por setores influentes da sociedade, como era o caso das concepções que de alguma forma davam corpo à Lebensphilosophie? Admitindo-se que a hostilidade se manifesta de forma sistemática, por meio de que concepções (filosóficas ou de qualquer outra natureza) ela se manifesta? Existe alguma ciência redefinindo seus rumos para tentar de alguma forma se ajustar a essas concepções? Revendo seus fundamentos? Abandonando certas concepções basilares em favor de outras? Apresentando o presente como um momento crítico de decisão e projetando as alternativas existenciais mutuamente excludentes que se colocam para quem importa decidir? Se a resposta para todas essas perguntas for "sim", há de se admitir que há no momento uma crise de legitimidade da ciência. No caso da Alemanha da República de Weimar, ponho minhas duas mãos no fogo. Em qualquer outro caso, não me arrisco. De qualquer forma, parece-me muito temerário postular a existência de uma "crise de legitimidade da ciência" sem que se tenha uma resposta bem fundamentada para todas essas perguntas. Temo que sem essas respostas o termo "crise de legitimidade da ciência" exprima tão somente o registro de um sentimento generalizado de mal-estar diante de uma situação circunstancialmente desoladora ou, como muitas vezes acontece, meramente um desalento pessoal, ainda que perfeitamente justificável.

\section{Referências bibliográficas}

BACHelard, Gaston. (1990), O materialismo racional. Tradução de João Gama. Lisboa, Edições 70.

BÁrbara, Lenin Bicudo. (2018), Investigaçôes sobre a ignorância humana. São Paulo, 861p., tese de doutorado, Faculdade de Filosofia, Letras e Ciências Humanas da Universidade de São Paulo.

Everett, Mary. (jul. 1937), “Man in the modern age”. The Sewanee Review, 45 (3): 358-370.

Feyerabend, Paul. (1985), Contra o método. 2 ed. Tradução de Octanny S. da Mota e Leônidas Hegenberg. Rio de Janeiro, Livraria Francisco Alves.

Forman, Paul. (1971), "Weimar culture, causality, and quantum theory, 1918-1927, Adaptation by German Physicists and mathematicians to a hostile intellectual environment". Historical Studies in the Physical Sciences, 3: 1-115. 
GRAF, Rüdiger. (dez. 2010), "Either-or: the narrative of crisis in Weimar Germany and in historiography". Central European History, 43 (4): 592-615.

Huizinga, Johan. (2017), Nas sombras do amanhã: diagnóstico da enfermidade espiritual do nosso tempo. Tradução de Sérgio Marinho. Goiânia, Editora e Livraria Caminhos.

HusSERL, Edmund. (1970) The crisis of European sciences and transcendental phenomenology. Evanston, Northwestern University Press.

ITokazu, Anastasia Guidi. (2008), "A natureza matemática: da alma da Terra como potência geometrizante no opúsculo Da neve hexagonal de Johannes Kepler”. Trans/Form/Ação, São Paulo, 31 (1): 73-86.

Jaspers, Karl. (1951), Man in the modern age. Londres, Routledge \& Kegan Paul Ltd.

Kroes, Peter A. (1988), "Newton's mathematization of physics in retrospect”. In: ScheURER, P. B. \& Debrock, G. (eds.). Newton's scientific and philosophical legacy. Dordrecht, Kluwer Academic Publishers, pp. 253-267.

Kunn, Thomas. (1962), The structure of scientific revolutions. Chicago, The University of Chicago Press.

Ortega y Gasset, José. (2001), A rebelião das massas. Edição eletrônica: Ridendo Castigat Mores. Tradução de Herrera Filho. Disponível em http://www.dominiopublico.gov.br/ download/texto/cv000060.pdf.

Ringer, Fritz K. (1969), The decline of the German mandarins: The German Academic Community, 1890-1933. Cambridge, Massachusetts, Harvard University Press.

Russell, Bertrand. (1974), ABC da relatividade. 4 ed. Tradução de Giasone Rebuá. Rio de Janeiro, Zahar.

Trizıo, Emiliano. (maio 2016), "What is the crisis of western sciences?”. Husserl Studies, 32 (3), 191-211.

\section{Resumo}

Três lugares para a crise de legitimidade da ciência

Neste ensaio defende-se a tese de que a "crise de legitimidade" da ciência é um fenômeno para o qual podem existir três lugares: o mundo celestial a que nos conduzem os escritos de autores como José Ortega y Gasset, Karl Jaspers, Johan Huizinga e Edmund Husserl; o mundo dantesco a que nos levam os escritos do filósofo da ciência Paul Feyerabend; e o mundo da realidade terrena a que nos conduzem os escritos de cientistas que reagem a uma situação de aberta hostilidade à ciência. Neste último caso, o termo "crise" não exprime uma desilusão pessoal com a ciência (como nos casos de Ortega y Gasset, Jaspers e Huizinga), nem as idiossincrasias de um sistema filosófico (como no caso de Husserl), nem as consequências funestas de uma bem-intencionada utopia libertária (como no caso de Feyerabend), mas uma redefinição dos caminhos a serem 
tomados por diferentes disciplinas científicas. Isso aconteceu na Alemanha da República de Weimar, a rigor o único lugar em que já existiu o que pode ser apropriadamente chamado de crise de legitimidade da ciência.

Palavras-chave: Crise da ciência; Utopia libertária; República de Weimar; História da ciência.

\section{Abstract}

Three places for "science's legitimacy" crisis

In this essay it is argued that there may be three places for science's "legitimacy crisis": the celestial world to which the writings of such authors as José Ortega y Gasset, Karl Jaspers, Johan Huizinga and Edmund Husserl lead us, the Dantesque world to which the writings of science philosopher Paul Feyerabend lead us, and the world of earthly reality to which the writings of scientists who react to a situation of open hostility to science lead us. In the latter, the term "crisis" does not express a personal disillusionment with science (as in the case of Ortega y Gasset, Jaspers, and Huizinga), nor the idiosyncrasies of a philosophical system (as in the case of Husserl), nor the dreadful consequences of a well-intentioned libertarian utopia (as in the case of Feyerabend), but a redefinition of the paths to be taken by different scientific disciplines, something that happened only once, in the Germany of the Weimar Republic, strictly speaking, the only place where what could properly be called "crisis of the legitimacy of science" has already existed.

Keywords: Crisis of science; Libertarian utopia; Weimar republic; History of science.

Texto recebido em 21/06/2021 e aprovado em 20/09/2021.

DOI: 10.11606/0103-2070.ts.2021.187549

Renan Springer de Freitas é professor titular de sociologia da Universidade Federal de Minas Gerais. Seu livro mais recente é Ciladas no caminho do conhecimento sociológico (2020, Ed. UfRJ). Membro do Conselho Editorial do periódico Philosophy of the Social Sciences. E-mail: renanweil@gmail.com. 